\title{
The relationship between glucocorticoid replacement and quality of life in 2737 hypopituitary patients
}

\section{Oskar Ragnarsson, Anders F Mattsson'1, John P Monson², Helena Filipsson Nyström, Ann-Charlotte Åkerblad', Maria Kołtowska-Häggström ${ }^{3}$ and Gudmundur Johannsson}

Department of Endocrinology, Diabetes and Metabolism, Sahlgrenska University Hospital and Sahlgrenska Academy, University of Gothenburg, Gröna Stråket 8, SE-413 45 Gothenburg, Sweden, 'Pfizer Endocrine Care, Sollentuna, Sweden, ${ }^{2}$ William Harvey Research Institute, Centre for Clinical Endocrinology, St Bartholomew's Hospital, Queen Mary, University of London, London, UK and ${ }^{3}$ Department of Women's and Children's Health, Uppsala University, Uppsala, Sweden

\begin{abstract}
Objective: Quality of life (QoL) is impaired in hypopituitary patients and patients with primary adrenal insufficiency. The aim of this study was to analyse the impact of glucocorticoid (GC) replacement on QoL. The main hypothesis was that ACTHinsufficient patients experience a dose-dependent deterioration in QoL.

Design, patients and methods: This was a retrospective analysis of data from KIMS (Pfizer International Metabolic Database). Data from 2737 adult GH-deficient (GHD) hypopituitary patients were eligible for analysis. Thirty-six per cent were ACTH sufficient and $64 \% \mathrm{ACTH}$ insufficient receiving a mean \pm s.D. hydrocortisone equivalent (HCeq) dose of $22.3 \pm 8.7 \mathrm{mg}$ (median 20.0). QoL at baseline and 1 year after commencement of GH replacement was assessed by the QoL-assessment of GHD in adults.

Results: At baseline, no significant difference in QoL was observed between ACTH-sufficient and -insufficient patients. Increasing HCeq dose was associated with worse QoL. Patients on HCeq $\leq 10 \mathrm{mg}$ had the best and patients receiving $\geq 25 \mathrm{mg}$ demonstrated the poorest QoL. At 1 year of GH replacement, the improvement in QoL did not differ between ACTH-sufficient and -insufficient patients, and no association was observed between HCeq dose and QoL improvement. Conclusion: Adult hypopituitary patients with untreated GHD receiving GC replacement have similar QoL as ACTH-sufficient patients. Among ACTH-insufficient patients, there is a dose-dependent association between increasing dose and impaired QoL. This association may be explained by supraphysiological GC exposure although it remains plausible that clinicians may have increased GC doses in order to address otherwise unexplained QoL deficits.
\end{abstract}

\section{Introduction}

Quality of life (QoL) is impaired in hypopituitary patients $(1,2,3,4)$. The reason is likely to be multifactorial, with aetiology, previous treatments, severity of the hypopituitarism and inadequate replacement therapy as potential important influencing factors $(4,5,6)$. Patients with primary and secondary adrenal insufficiency (AI) also have impaired QoL $(7,8,9)$. In a recent survey including
1245 participants with AI, two-thirds reported compromised subjective health status with a negative impact on their social, work and family life (10).

Adverse cardiovascular risk profile (11), low bone mineral density $(12,13)$ and increased mortality rate (14) have all been associated with supraphysiological glucocorticoid (GC) replacement doses in patients with AI. (c) 2014 European Society of Endocrinology Printed in Great Britain
Published by Bioscientifica Ltd. 
Higher GC doses are also associated with more severe impairments of subjective health status in patients with AI $(7,8)$. In a randomised, double-blind, crossover study including 18 patients with secondary AI, treatment with $10+5 \mathrm{mg}$ of hydrocortisone (HC) had more favourable effects on well-being than treatment with either $10+5+$ $5 \mathrm{mg}$ of $\mathrm{HC}$ or $5 \mathrm{mg}$ of prednisolone (15). Also, recent findings suggest that changed GC exposure time profile achieved with a HC dual-release formulation has a beneficial effect on QoL compared with conventional HC replacement (16).

The overall aim of this study was to analyse the impact of GC replacement therapy on QoL in patients with pituitary insufficiency. More specifically, the aims were to compare QoL in adrenocorticotropic hormone (ACTH)insufficient and -sufficient patients before and after growth hormone (GH) replacement therapy and to analyse the relationship between GC doses and/or type of GCs on QoL. In the light of the previous findings, indicating that adverse cardiovascular risk profile is associated with increasing GC doses (11), the main hypothesis was that ACTH-insufficient patients have a dose-dependent deteriorated QoL.

\section{Material and methods}

\section{Patients and study design}

This was a retrospective analysis of data from adult GH-deficient (GHD) hypopituitary patients obtained from KIMS (Pfizer International Metabolic Database) who were enrolled between 1994 and January 2012. Data from baseline (at entry into KIMS) and at 1 year after commencement of GH replacement were analysed.

In January 2012, 16480 patients had been included in the database. The following patients were excluded from the current analysis: i) patients receiving GH replacement at entry into the database (non-naïve; $n=4490$ ); ii) patients not fulfilling the criteria for GHD $(n=4201$; see below); iii) patients with incomplete data concerning QoL measurements $(n=2146)$ or background characteristics $(n=182)$; iv) ACTH-insufficient patients with incomplete data concerning GC type or GC dose $(n=1000)$; v) patients who did not receive treatment with GH after entry into KIMS $(n=747)$; vi) patients with $<1$ year of follow-up $(n=534)$; vii) patients previously treated for Cushing's disease or acromegaly $(n=312)$; viii) ACTHinsufficient patients receiving replacement with prednisolone or dexamethasone $(n=47)$; ix) patients registered as ACTH sufficient but receiving GC treatment $(n=43)$; $x)$ patients switched from one to another form of GC during the first year of GH replacement $(n=29)$; and xi) patients from countries with fewer than ten patients registered in KIMS $(n=12)$.

In total, 2737 adult patients were included in the analysis. All patients had GHD, defined as one of the following criteria: i) $\mathrm{GH}$ peak $<3 \mu \mathrm{g} / \mathrm{l}$ during insulin tolerance test or glucagon stimulation; ii) suboptimal BMI-dependent GH peak during GHRH-arginine stimulation according to international guidelines; iii) $\mathrm{GH}$ peak $<0.4 \mu \mathrm{g} / \mathrm{l}$ during arginine stimulation; or iv) insulin-like growth factor 1 (IGF1) SDS $<-2$ in combination with three or more additional pituitary hormone deficiencies (17). The majority of the patients (77\%) had never received GH treatment previously (truenaïve) while $23 \%$ had, although not during the preceding 6 months prior to entry (semi-naïve).

Nine hundred and eighty-seven (36\%) patients were ACTH sufficient and 1750 (64\%) were ACTH insufficient. Of the ACTH-insufficient patients, 1355 (77\%) were receiving replacement therapy with HC and 395 (23\%) with cortisone acetate (CA). For patients receiving treatment with $\mathrm{CA}$, the $\mathrm{HC}$ equivalent (HCeq) dose was calculated. Thus, the equivalent dose of $20 \mathrm{mg} \mathrm{HC}$ was $25 \mathrm{mg}$ for CA as previously described (11). Information on the specific diagnostic criteria used for diagnosis of ACTH insufficiency is not included in KIMS and is therefore dependent on the clinical practice at each participating centre.

\section{Methods}

Data on background characteristics, height and weight were obtained from KIMS as reported by each participating clinical centre. BMI was calculated as weight $/$ height $^{2}$ $\left(\mathrm{kg} / \mathrm{m}^{2}\right)$.

QoL was assessed by the QoL-assessment of GHD in adults (QoL-AGHDA) questionnaire $(18,19)$. The questionnaire consists of 25 statements (items) that the patients either affirm or deny (yes/no). Higher numerical scores, to a maximum of 25 , denote poorer QoL. Besides total score, the following five dimensions are also evaluated by the QoL-AGHDA questionnaire: memory (six items); tiredness (seven items); tenseness (three items); social isolation (five items); and self-confidence (four items). As a number of items differ, a standardised score (proportion), taking values between 0 and 1 , was calculated and used for each dimension, where a higher proportion indicates higher number of affirmative items in each patient. Level of physical activity and satisfaction with physical activity were assessed using visual analog 
scales, being a part of the KIMS Patient Life Situation Form. High numerical values indicate high levels of physical activity and a greater degree of satisfaction with the level of physical activity (20).

Serum IGF1 concentrations were measured at a central facility, from 1994 to 1997, at Kabi Pharmacia (Stockholm, Sweden) and, thereafter, at Sahlgrenska University Hospital (Gothenburg, Sweden). Between 1994 and November 2002, serum IGF1 was measured by RIA after acid/ethanol precipitation of IGF-binding proteins (Nichols Institute, San Juan Capistrano, CA, USA), followed by a chemiluminescence immunoassay (Nichols Advantage System). After September 2006, Immulite 2500 (Diagnostic Products Corp., Siemens, Deerfield, IL, USA) was used. For each assay, ageand gender-specific reference ranges were used to determine IGF1 SDS. Reference ranges and consistency of IGF1 SDS values between assays were validated internally.

\section{Ethical considerations}

The KIMS protocol was approved by the Institutional Review Boards, as required by local regulations in each participating country. Before registration in the database, written informed consent was obtained from patients, according to country regulations. KIMS is conducted according to the Declaration of Helsinki.

\section{Statistical analysis}

For descriptive statistics, values are expressed as mean \pm s.D., or median (5th-95th percentiles) or proportions, depending on type of variable. The unadjusted mean comparisons between groups were performed by $t$-tests for numerical variables (PROC TTEST, SAS version 9.2; SAS Institute, Cary, NC, USA). For nominal or categorical variables (proportions), $\chi^{2}$ tests were performed (PROC FREQ, SAS version 9.2).

The analyses of baseline outcome variables and 1-year change outcome variables were performed by regression methods for unbalanced designs (PROC GLM, SAS version 9.2). Group comparisons, using mean values, were in baseline analyses adjusted for age at entry into KIMS, gender, thyroid-stimulating hormone (TSH) deficiency, aetiology, onset of disease (adult vs childhood), IGF1 SDS, weight and country. Baseline HCeq dose-response analyses were confined to the ACTH-insufficient group and further adjusted for treatment group (HC vs CA) and height.

First-year delta analyses were additionally controlled for numerical baseline QoL-AGHDA total score, baseline QoL-AGHDA total score squared, numerical GH dose $\mathrm{mg} /$ day at 1-year visit and GH dose $\mathrm{mg}$ /day as a dummy variable ( $<0.1 \mathrm{vs}>0.1 \mathrm{mg} /$ day).

Countries were divided into three different categories based on similarity in mean baseline total QoL-AGHDA score. Argentina $(n=38)$, Austria $(n=41)$, Switzerland $(n=31)$, Czech Republic $(n=78)$, Germany $(n=533)$, Denmark $(n=62)$, Sweden $(n=418)$, Slovakia $(n=39)$ and the USA $(n=50)$ formed the category with low QoLAGHDA scores in relation to other participating countries. Belgium $(n=316)$, Spain $(n=282)$, France $(n=114)$, Greece $(n=18)$ and The Netherlands $(n=196)$ the category with medium QoL-AGHDA scores and the UK $(n=497)$ and Ireland $(n=24)$ the category with high QoL-AGHDA scores. CIs were Wald based. Statistical significance was set to $P<0.05$.

\section{Results}

\section{Baseline characteristics}

The most common underlying cause of hypopituitarism was non-functioning pituitary adenoma (31\%), idiopathic pituitary insufficiency (12\%), craniopharyngioma (12\%), prolactinoma (10\%), treatment for intracranial tumours distant from the pituitary (4\%), Sheehan's syndrome (4\%) and empty sella syndrome (4\%) (Table 1).

In comparison with ACTH-sufficient patients, ACTHinsufficient patients were older, taller, had more often adult-onset GHD and lower IGF1 SDS (Table 2). A higher proportion of ACTH-insufficient patients were men and had more often received treatment with radiotherapy and/or surgery. Also, the aetiology of pituitary insufficiency differed between the groups (Table 1), and ACTH-insufficient patients had more often concomitant TSH- and sex hormone deficiency, as well as diabetes insipidus (Table 2).

The mean \pm s.D. HCeq dose was $22.3 \pm 8.7 \mathrm{mg}$ (median 20.0); $21.9 \pm 8.4 \mathrm{mg}$ in HC-treated patients and $23.6 \pm 9.3$ in CA-treated patients $(P<0.001)$. HCeq doses were significantly higher in ACTH-insufficient men $(23.4 \pm$ $8.5)$ than in women $(20.8 \pm 8.6 ; P<0.0001)$. The majority of patients receiving CA came from Sweden $(n=219,55 \%)$, The Netherlands $(n=67,17 \%)$ and Germany $(n=56,14 \%)$.

\section{The relationship between GC replacement and QoL at baseline}

Unadjusted QoL-AGHDA score at baseline was significantly lower in ACTH-insufficient patients $(10.1 \pm 6.9)$ compared with ACTH-sufficient patients (11.1 \pm 7.4 , $P=0.001)$. 
Table 1 Aetiology of pituitary insufficiency in the study population. Data are presented as $n(\%)$.

\begin{tabular}{lcc}
\cline { 3 - 3 } & All $(n=2737)$ \\
\hline Non-functioning pituitary adenoma & & $845(31 \%)$ \\
Idiopathic pituitary insufficiency & & $338(12 \%)$ \\
Craniopharyngioma & $324(12 \%)$ \\
Prolactinoma & $277(10 \%)$ \\
Treatment for cranial tumours & $122(4 \%)$ \\
$\quad$ distant from the pituitary & \\
Other pituitary adenoma & $112(4 \%)$ \\
Sheehan's syndrome & $105(4 \%)$ \\
Empty sella syndrome & $92(4 \%)$ \\
Head trauma & $57(2 \%)$ \\
Pituitary cysts & $48(2 \%)$ \\
Meningioma & $38(1 \%)$ \\
Hypophysitis & $32(1 \%)$ \\
Other & $347(13 \%)$ \\
\hline
\end{tabular}

After adjustment for age, gender, weight, aetiology, country, year at entry into KIMS, onset of pituitary disease (childhood vs adult onset), TSH deficiency and IGF1 SDS, no difference in QoL-AGHDA score was observed between ACTH-sufficient (11.1 (95\% CI 10.6-11.7)) and ACTHinsufficient patients (11.0 (95\% CI 10.5-11.5); $P=0.8$ ) (Table 3). Also, no difference in QoL-AGHDA score was seen in HC-treated patients (11.1 (95\% CI 10.4-11.8)) compared with CA-treated patients (10.4 (95\% CI 9.4-11.3); $P=0.12)$.

After adjustment for the same variables as above, in addition to type of GC (HC or CA), there was a significant association with increasing $\mathrm{HCeq}$ dose and worsening QoL-AGHDA score (Fig. 1f). Patients with HCeq doses lower than $10 \mathrm{mg}$ /day had the lowest QoL-AGHDA score,

\begin{tabular}{c}
\hline $\begin{array}{c}\text { ACTH sufficient } \\
(n=987)\end{array}$ \\
\hline $256(26 \%)$ \\
$199(20 \%)$ \\
$32(3 \%)$ \\
$104(11 \%)$ \\
$72(7 \%)$ \\
$42(4 \%)$ \\
$15(2 \%)$ \\
$42(4 \%)$ \\
$30(3 \%)$ \\
$10(1 \%)$ \\
$21(2 \%)$ \\
$4(0.5 \%)$ \\
$160(16 \%)$ \\
\hline
\end{tabular}

\begin{tabular}{c}
\hline $\begin{array}{c}\text { ACTH insufficient all } \\
(n=1750)\end{array}$ \\
\hline $589(33 \%)$ \\
$139(8 \%)$ \\
$292(17 \%)$ \\
$173(10 \%)$ \\
$50(3 \%)$ \\
$70(4 \%)$ \\
$90(5 \%)$ \\
$50(3 \%)$ \\
$27(2 \%)$ \\
$38(2 \%)$ \\
$17(1 \%)$ \\
$28(2 \%)$ \\
$187(11 \%)$ \\
\hline
\end{tabular}

and patients with doses of $25 \mathrm{mg}$ or above had the highest scores $(P$ for trend $=0.006)$.

\section{The relationship between GC replacement and} different dimensions of QoL and physical activity at baseline

There were significant associations between increasing HCeq dose and problems with tiredness, tenseness and social isolation, but not with memory and self-confidence (Fig. 1a, b, c, d and e). Level of physical activity and satisfaction with physical activity were not associated with HCeq dose (data not shown).

Patients on CA had fewer problems with tenseness $(0.47$ (95\% CI 0.42-0.53)) than HC-treated patients (0.54 (95\% CI

Table 2 Baseline characteristics of the study population. Data are presented as mean \pm s.D. or $n$ (\%).

\begin{tabular}{l} 
Variable \\
\hline Age (years) \\
No. of women (\%) \\
Weight $(\mathrm{kg})$ \\
Height $(\mathrm{cm})$ \\
BMI (kg/m²) \\
True-naïve \\
Semi-naïve \\
Childhood onset \\
Adult onset \\
Tumour treatment, $n$ (\%) \\
Surgery \\
Radiotherapy \\
Surgery and radiotherapy \\
Pituitary hormone \\
deficiencies, $n$ (\%) \\
TSH \\
LH/FSH \\
ADH \\
IGF1 (SDS) \\
\end{tabular}

\begin{tabular}{c}
$\begin{array}{c}\text { ACTH sufficient } \\
(n=987)\end{array}$ \\
\hline $41.3 \pm 15.0$ \\
$515(52 \%)$ \\
$79.9 \pm 21.1$ \\
$167 \pm 11.2$ \\
$28.4 \pm 6.4$ \\
$720(73 \%)$ \\
$267(27 \%)$ \\
$281(28 \%)$ \\
$706(72 \%)$ \\
\\
$261(26 \%)$ \\
$56(6 \%)$ \\
$172(17 \%)$ \\
\\
$390(40 \%)$ \\
$529(54 \%)$ \\
$90(9 \%)$ \\
$-1.9 \pm 1.9$ \\
\hline
\end{tabular}

\begin{tabular}{c}
\hline $\begin{array}{c}\text { ACTH insufficient } \\
\text { all }(n=1750)\end{array}$ \\
\hline $44.7 \pm 14.9$ \\
$792(45 \%)$ \\
$81.1 \pm 19.2$ \\
$169 \pm 10.5$ \\
$28.3 \pm 5.8$ \\
$1374(79 \%)$ \\
$376(21 \%)$ \\
$332(19 \%)$ \\
$1418(81 \%)$ \\
$734(42 \%)$ \\
$61(4 \%)$ \\
$427(24 \%)$ \\
\\
$1596(91 \%)$ \\
$1568(90 \%)$ \\
$562(32 \%)$ \\
$-2.6 \pm 2.0$
\end{tabular}

\begin{tabular}{|c|c|}
\hline $\boldsymbol{P}$ & $\begin{array}{l}\text { Hydrocortisone } \\
\quad(n=1355)\end{array}$ \\
\hline$<0.0001$ & $43.4 \pm 14.7$ \\
\hline 0.0005 & $623(46 \%)$ \\
\hline 0.15 & $80.9 \pm 19.5$ \\
\hline$<0.0001$ & $168 \pm 10.4$ \\
\hline 0.5 & $28.5 \pm 6.0$ \\
\hline \multirow[t]{2}{*}{0.001} & $1037(77 \%)$ \\
\hline & $318(23 \%)$ \\
\hline \multirow[t]{2}{*}{$<0.0001$} & $286(21 \%)$ \\
\hline & $1069(79 \%)$ \\
\hline \multirow[t]{3}{*}{$<0.0001$} & $560(41 \%)$ \\
\hline & $46(3 \%)$ \\
\hline & $328(24 \%)$ \\
\hline$<0.0001$ & $1226(91 \%)$ \\
\hline$<0.0001$ & $1210(89 \%)$ \\
\hline$<0.0001$ & $454(34 \%)$ \\
\hline 0.8 & $-2.6 \pm 2.0$ \\
\hline
\end{tabular}

\begin{tabular}{c}
$\begin{array}{c}\text { Cortisone acetate } \\
(n=395)\end{array}$ \\
\hline $48.9 \pm 14.6$ \\
$169(43 \%)$ \\
$81.8 \pm 18.1$ \\
$172 \pm 10.3$ \\
$27.5 \pm 5.0$ \\
$337(85 \%)$ \\
$58(15 \%)$ \\
$46(12 \%)$ \\
$349(88 \%)$ \\
$174(44 \%)$ \\
$15(4 \%)$ \\
$99(25 \%)$ \\
\\
$370(94 \%)$ \\
$358(91 \%)$ \\
$108(27 \%)$ \\
$-2.8 \pm 2.1$ \\
\end{tabular}

\begin{tabular}{c}
\hline \multicolumn{1}{c}{$\boldsymbol{P}$} \\
\hline$<0.0001$ \\
0.3 \\
0.4 \\
$<0.0001$ \\
0.001 \\
0.0002 \\
$<0.0001$ \\
\\
0.5 \\
\\
0.05 \\
0.3 \\
0.15 \\
\hline
\end{tabular}

www.eje-online.org 
Table 3 Data on quality of life (QoL), dimensions of QoL (both assessed by the QoL-assessment of growth hormone (GH) deficiency in adults (QoL-AGHDA) questionnaire) and physical activity at baseline and change at 1 year on GH replacement. Data are presented as mean $(95 \% \mathrm{Cl})$.

\begin{tabular}{l}
\hline \\
\hline QoL-AGHDA score \\
Total \\
Memory \\
Tiredness \\
Tenseness \\
Social isolation \\
Self-confidence \\
Physical activity \\
Level \\
Satisfaction
\end{tabular}

\begin{tabular}{|c|c|}
\hline \multicolumn{2}{|r|}{ Baseline } \\
\hline ACTH sufficient & ACTH insufficient \\
\hline 11.1 (10.6 to 11.7 ) & $11.0(10.5$ to 11.5$)$ \\
\hline 0.48 (0.45 to 0.51$)$ & 0.48 (0.46 to 0.51$)$ \\
\hline 0.55 (0.52 to 0.58$)$ & $0.53(0.50$ to 0.56$)$ \\
\hline $0.53(0.50$ to 0.56$)$ & $0.53(0.50$ to 0.56$)$ \\
\hline $0.33(0.30$ to 0.35$)$ & 0.31 (0.29 to 0.34$)$ \\
\hline $0.30(0.27$ to 0.33$)$ & 0.31 ( 0.29 to 0.33$)$ \\
\hline 35 (32 to 37 ) & 37 (35 to 39 ) \\
\hline 35 (32 to 37$)$ & 37 (35 to 40 ) \\
\hline
\end{tabular}

\begin{tabular}{|c|c|c|}
\hline \multicolumn{3}{|c|}{ Change at 1 year } \\
\hline ACTH sufficient & ACTH insufficient & $P$ \\
\hline $\begin{array}{l}-4.0(-4.5 \text { to }-3.5) \\
-0.13(-0.16 \text { to }-0.11) \\
-0.23(-0.26 \text { to }-0.20) \\
-0.17(-0.20 \text { to }-0.14) \\
-0.11(-0.13 \text { to }-0.09) \\
-0.09(-0.11 \text { to }-0.07)\end{array}$ & $\begin{array}{l}-3.7(-4.2 \text { to }-3.2) \\
-0.13(-0.16 \text { to }-0.11) \\
-0.20(-0.22 \text { to }-0.17) \\
-0.17(-0.20 \text { to }-0.14) \\
-0.11(-0.13 \text { to }-0.09) \\
-0.11(-0.13 \text { to }-0.09)\end{array}$ & $\begin{array}{l}0.4 \\
1.0 \\
0.1 \\
1.0 \\
0.9 \\
0.3\end{array}$ \\
\hline $\begin{array}{l}12(10 \text { to } 15) \\
13 \text { (10 to } 16)\end{array}$ & $\begin{array}{r}7(5 \text { to } 10) \\
11(8 \text { to } 14)\end{array}$ & $\begin{array}{l}0.1 \\
0.4\end{array}$ \\
\hline
\end{tabular}

0.51-05.8), $P<0.01)$. No other QoL dimension differed between the groups at baseline (data not shown).

\section{The relationship between GC replacement and QoL at 1 year on GH replacement therapy}

Information at 1 year on GH treatment was available for 2010 patients; 737 ACTH sufficient, 965 on HC and 308 on CA. The mean GH dose at 1 year was $0.39 \pm 0.23 \mathrm{mg}$ in ACTH-insufficient patients and $0.39 \pm 0.25$ in ACTHsufficient patients. The HCeq doses were unchanged at 1 year, $21.8 \pm 8.4$ in HC-treated patients and $23.5 \pm 9.4$ in CA-treated patients. The IGF1 SDS increased to comparable levels in ACTH-sufficient $(0.03 \pm 1.52)$ and ACTHinsufficient patients $(0.01 \pm 1.76 ; P=0.9)$. The mean \pm s.D. increase in IGF1 SDS ( $\triangle \mathrm{IGF} 1 \mathrm{SDS})$ was $2.64 \pm 1.85$ in ACTH insufficient and $1.90 \pm 1.57$ in ACTH-sufficient patients.

At 1 year on GH replacement, QoL-AGHDA score decreased significantly in both ACTH-sufficient and insufficient patients compared with baseline. Patients with higher QoL-AGHDA score at baseline demonstrated a greater improvement (Fig. 2). After adjustment for age, gender, weight, aetiology, year at entry into KIMS, onset of pituitary disease (childhood vs adult onset), TSH deficiency, country, GH dose, IGF1 SDS and AGHDA score at baseline, the mean decrease in QoL-AGHDA score was similar between the groups $(P=0.54) ;-3.93(95 \% \mathrm{CI}-4.38$ to -3.48$)$ in ACTHsufficient and -3.68 (95\% CI -4.10 to -3.25$)$ in ACTHinsufficient patients. The treatment response in QoLAGHDA score did not differ between patients receiving HC $(-3.56(95 \% \mathrm{CI}-4.12$ to -3.00$))$ and CA $(-4.05$ (95\% CI -4.87 to -3.23$) ; P=0.22$ ).

No significant association was observed between HCeq dose and improved QoL-AGHDA score. Similarly, the changes from baseline in the dimensions of tiredness, tenseness, social isolation, memory, self-confidence, level of physical activity and satisfaction with physical activity were not different between the groups and did not show an association with HCeq dose.

\section{Discussion}

This study comprising more than 2500 hypopituitary patients with GHD demonstrates that those receiving GC

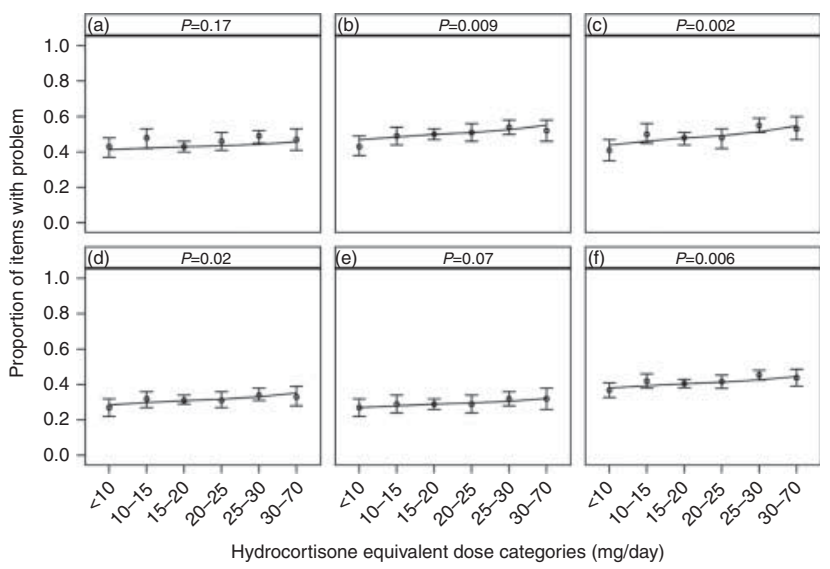

\section{Figure 1}

Graphs showing proportions of items within a QoL-dimension that the patients expressed problems with at baseline:

(a) memory, (b) tiredness, (c) tenseness, (d) social isolation, (e) self-confidence and ( $f$ ) total QoL-AGHDA score in relation to different hydrocortisone equivalent doses at baseline in 1750 ACTH-insufficient patients with untreated growth hormone deficiency. $P$ value given above respective panel is the $P$ value for trend. 


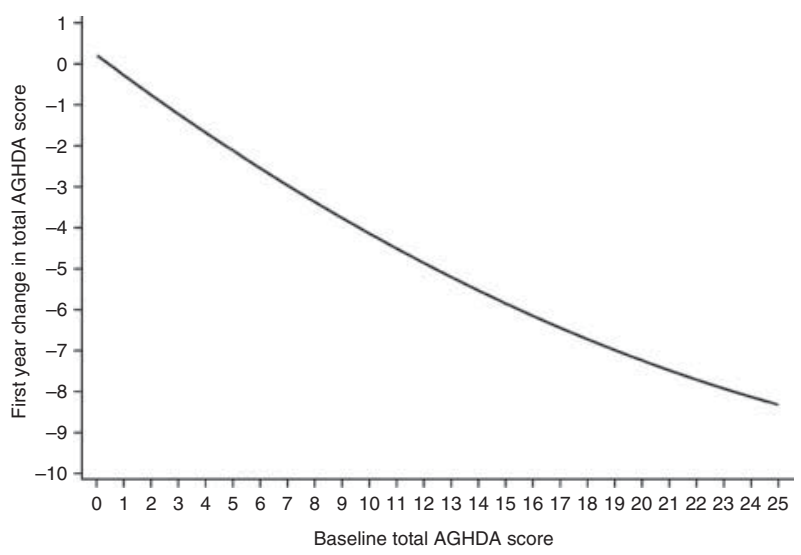

\section{Figure 2}

The relationship between the QoL-AGHDA score at baseline and the mean change in total QoL-AGHDA score after 1 year of $\mathrm{GH}$ replacement. The figure demonstrates that patients with the highest QoL-AGHDA score at baseline (most severely impaired QoL) improve their score most after 1 year on $\mathrm{GH}$. No statistically significant difference was observed between ACTH-sufficient and -insufficient patients. Therefore, the curve represents the change in both $\mathrm{ACTH}$-insufficient and -sufficient patients.

replacement do not have worse QoL compared with ACTH-sufficient patients. However, and importantly, a significant association between GC daily doses and QoL was observed, whereby patients receiving low GC doses had the best outcome and patients receiving HCeq doses of $25 \mathrm{mg}$ or more had the most severely affected QoL. Three of five dimensions of QoL were also negatively affected by increasing GC doses, i.e. tiredness, tenseness and social isolation.

Several previous studies have demonstrated that QoL is impaired in patients with $\mathrm{AI}$ in comparison with healthy controls $(7,8,9)$. In comparison with patients with primary AI, patients with secondary AI seem to have even more severely affected subjective well-being (8). In two cross-sectional studies from Germany including more than 200 patients with both primary and secondary AI, patients on HC doses exceeding $30 \mathrm{mg} /$ day had more severely impaired QoL compared with patients on lower doses $(7,8)$. Our results, showing a dose-related association with measures of QoL, are in accordance with these $(7,8)$ and other previous smaller studies $(15,21)$. The results are also in line with a study on 2424 hypopituitary patients from the KIMS database where the impact of GC replacement on cardiovascular risk factors was analysed (11). In that study, GC replacement had a clear dose- related association with increase in BMI, triglycerides, total cholesterol and LDL cholesterol. Interestingly, in our study, no difference was observed between ACTH-insufficient and -sufficient patients. Therefore, it seems likely that factors other than ACTH insufficiency have a greater impact on QoL in hypopituitary patients.

Historically, GC replacement doses used to treat adrenal insufficient patients were considerably higher than the doses in use today $(22,23)$. Based on studies showing that normal cortisol production rate in humans corresponds to 15-20 mg HC/day (24), prescription of generally lower GC doses is currently recommended $(23,25,26,27)$. The results from our study, together with previous findings showing that high GC doses are associated with increased cardiovascular risk (11), osteoporosis $(12,13)$ and mortality (14), support this approach. A possible explanation for our observation of the association between high GC doses and unfavourable QoL is a supraphysiological GC exposure. Supporting this hypothesis are studies on patients with overt (28) and subclinical hypercortisolism (29) demonstrating significantly impaired QoL that improves after treatment. However, our results might also be explained by the possibility that patients who receive relatively high GC doses represent a group with impaired QoL where an empirical increase in GC dose, and subsequent unintentional over replacement, has been tried in an attempt to improve general well-being. It is well known that short-term GC treatment may induce a sense of well-being, also called steroid euphoria (30), and in some cases lead to drug dependency (31). Another possible explanation may be that patients receiving high GC doses may represent a group with more severe ACTH insufficiency, and subsequently have more severely impaired QoL. In such a case, one can speculate that impaired QoL is related to more severe disease and not to high GC doses. Nevertheless, the dose-dependent association between increasing dose and impaired QoL indicates that the relation with the dosing rather than disease as such is of greater importance. Based on this observation, we suggest avoiding too high GC replacement doses whenever possible.

Not only the total GC daily doses but also the type of GC and regimens may influence QoL in patients with AI. There are studies showing that thrice daily dosing results in improved well-being (22), while another study did not demonstrate that thrice daily dosing was superior to twice daily (7). As the frequency of GC dosing is not registered in KIMS, the influence of GC regimes could not be analysed in the current study. Recently, a modified-release HC formulation has been developed that better mimics physiological cortisol exposure (16). In comparison with 
patients receiving conventional thrice daily dosing, treatment with same total daily HC dose with the new formulation resulted in improved well-being and more favourable effects on fatigue (16). In our study, we attempted to evaluate the effect of cortisol exposure by calculating HC dose per kilogram body weight. With this crude surrogate measure, no effects on QoL were demonstrated (data not shown). Similarly, the present study, after adjustment for potential confounders, did not detect any overall difference between patients treated with $\mathrm{HC}$ and $\mathrm{CA}$, which is in accordance with previous findings (32).

Several studies have demonstrated beneficial effects on QoL during GH replacement therapy in adult GHD hypopituitary patients $(2,3,33)$ and that more severely affected QoL at baseline predicts a better GH treatment response (34). This is the first study to specifically evaluate whether the effect of GH replacement therapy on QoL is influenced by GC replacement treatment. GH/IGF1 inhibits the activity and expression of $11 \beta$-hydroxysteroid dehydrogenase type 1 (35), an enzyme that converts the inactive metabolite cortisone to the active hormone cortisol (36). In patients with pituitary insufficiency and previously undiagnosed partial ACTH deficiency, GH replacement reduces cortisol concentrations in serum and urine as well as the cortisol response to ACTH stimulation or insulininduced hypoglycaemia (37). Hypothetically, it is therefore possible that ACTH-insufficient patients, on fixed but relatively low GC doses and with inability to compensate for the decreased cortisol levels, have a different therapeutic response to GH replacement than their ACTH-sufficient counterparts. In the current study, however, the improvement in QoL was similar in GC-treated and ACTH-sufficient patients, and no association between HC dose and the improvement in QoL at 1 year was observed. It should also be noted that similar HCeq dose does not necessarily indicate similar tissue GC exposure, as determined by the ratio of urine 11-hydroxy/11-oxo cortisol metabolites, in patients on $\mathrm{HC}$ and CA (38).

This study has limitations. First and foremost is to acknowledge the retrospective design and the heterogeneity of the study cohort with patients from 16 countries and having a wide range of pituitary diseases. In fact, these and several other important background variables (outlined in Tables 1 and 2) were unequally distributed between ACTH-sufficient and -insufficient patients including other pituitary hormone deficiencies and their replacement and thereby are a potential source of confounders. It was therefore of importance to adjust for as many confounders as possible in the statistical analysis and thereby to minimise their influence on the results.
The same argument accounts for comparison between HCand CA-treated patients. In addition, information in KIMS on ACTH status is dependent on clinical practice by each participating centre. Therefore, it is possible that some patients considered to be ACTH sufficient may actually be insufficient and vice versa. This is a limitation of our study and may in fact, at least partially, explain why no difference in QoL-AGHDA score was observed between ACTH-sufficient and -insufficient patients. However, the primary aim of the current study was to analyse the impact of GC replacement on QoL and, instead of comparison with healthy individuals, ACTH-sufficient patients served as a control group. Finally, we used the QoL-AGHDA questionnaire to evaluate QoL. The questionnaire was developed to assess well-being in adult GHD and demonstrates sensitivity in this group of patients. Therefore, it is likely that certain important aspects of QoL impairment in patients with an excess of GCs are not being captured by the QoL-AGHDA. Recently, a diseasespecific questionnaire has been developed for patients with primary AI (39). It is possible that such a questionnaire would have been more appropriate than the one we used, although its properties lack the specificity to capture GHD-related problems.

In conclusion, adult hypopituitary patients with untreated GHD receiving GC replacement therapy have similar QoL as ACTH-sufficient patients. Among patients with ACTH insufficiency, however, there is a dosedependent association between increasing dose and impaired QoL that may be explained by supraphysiological GC exposure or an empirical increasing in GC dose in patients with negatively affected QoL.

\section{Declaration of interest}

O Ragnarsson has received lecture fees from Pfizer. M KołtowskaHäggström was and A F Mattsson and A-C Åkerblad are permanent employees of Pfizer Health AB. G Johannsson has received lecture fees from Eli Lilly, Merck Serono, NovoNordisk, Otsuka and Pfizer and is a consultant for Viropharma and Astra Zeneca. J P Monson and H Filipsson Nyström have nothing to declare.

\section{Funding}

KIMS is sponsored by Pfizer, Inc. O Ragnarsson, J P Monson, H Filipsson Nyström and G Johannsson were not compensated for their contributions to this manuscript.

\section{Acknowledgments}

The authors express their gratitude to the KIMS investigators and their patients for the provided primary data. 


\section{References}

1 Carroll PV, Christ ER, Bengtsson BA, Carlsson L, Christiansen JS, Clemmons D, Hintz R, Ho K, Laron Z, Sizonenko P et al. Growth hormone deficiency in adulthood and the effects of growth hormone replacement: a review. Growth Hormone Research Society Scientific Committee. Journal of Clinical Endocrinology and Metabolism $1998 \mathbf{8 3}$ 382-395. (doi:10.1210/jcem.83.2.4594)

2 Spielhagen C, Schwahn C, Moller K, Friedrich N, Kohlmann T, Moock J, Koltowska-Haggstrom M, Nauck M, Buchfelder M \& Wallaschofski H. The benefit of long-term growth hormone (GH) replacement therapy in hypopituitary adults with GH deficiency: results of the German KIMS database. Growth Hormone \& IGF Research 201121 1-10. (doi:10.1016/ j.ghir.2010.10.005)

3 Koltowska-Haggstrom M, Mattsson AF, Monson JP, Kind P, Badia X, Casanueva FF, Busschbach J, Koppeschaar HP \& Johannsson G. Does long-term GH replacement therapy in hypopituitary adults with GH deficiency normalise quality of life? European Journal of Endocrinology 2006155 109-119. (doi:10.1530/eje.1.02176)

4 Burman P \& Deijen JB. Quality of life and cognitive function in patients with pituitary insufficiency. Psychotherapy and Psychosomatics 199867 154-167. (doi:10.1159/000012276)

5 van der Klaauw AA, Kars M, Biermasz NR, Roelfsema F, Dekkers OM, Corssmit EP, van Aken MO, Havekes B, Pereira AM, Pijl H et al. Diseasespecific impairments in quality of life during long-term follow-up of patients with different pituitary adenomas. Clinical Endocrinology 2008 69 775-784. (doi:10.1111/j.1365-2265.2008.03288.x)

6 Santos A, Resmini E, Martinez MA, Marti C, Ybarra J \& Webb SM. Quality of life in patients with pituitary tumors. Current Opinion in Endocrinology, Diabetes, and Obesity 200916 299-303. (doi:10.1097/ MED.0b013e32832cdec9)

7 Bleicken B, Hahner S, Loeffler M, Ventz M, Decker O, Allolio B \& Quinkler M. Influence of hydrocortisone dosage scheme on healthrelated quality of life in patients with adrenal insufficiency. Clinical Endocrinology 201072 297-304. (doi:10.1111/j.1365-2265.2009.03596.x)

8 Hahner S, Loeffler M, Fassnacht M, Weismann D, Koschker AC, Quinkler M, Decker O, Arlt W \& Allolio B. Impaired subjective health status in 256 patients with adrenal insufficiency on standard therapy based on cross-sectional analysis. Journal of Clinical Endocrinology and Metabolism 200792 3912-3922. (doi:10.1210/jc.2007-0685)

9 Lovas K, Loge JH \& Husebye ES. Subjective health status in Norwegian patients with Addison's disease. Clinical Endocrinology 200256 581-588. (doi:10.1046/j.1365-2265.2002.01466.x)

10 Forss M, Batcheller G, Skrtic S \& Johannsson G. Current practice of glucocorticoid replacement therapy and patient-perceived health outcomes in adrenal insufficiency - a worldwide patient survey. BMC Endocrine Disorders 201212 8. (doi:10.1186/1472-6823-12-8)

11 Filipsson H, Monson JP, Koltowska-Haggstrom M, Mattsson A \& Johannsson G. The impact of glucocorticoid replacement regimens on metabolic outcome and comorbidity in hypopituitary patients. Journal of Clinical Endocrinology and Metabolism 200691 3954-3961. (doi:10.1210/jc.2006-0524)

12 Ragnarsson O, Nystrom HF \& Johannsson G. Glucocorticoid replacement therapy is independently associated with reduced bone mineral density in women with hypopituitarism. Clinical Endocrinology 201276 246-252. (doi:10.1111/j.1365-2265.2011.04174.x)

13 Zelissen PM, Croughs RJ, van Rijk PP \& Raymakers JA. Effect of glucocorticoid replacement therapy on bone mineral density in patients with Addison disease. Annals of Internal Medicine 1994120 207-210. (doi:10.7326/0003-4819-120-3-199402010-00005)

14 Sherlock M, Reulen RC, Alonso AA, Ayuk J, Clayton RN, Sheppard MC, Hawkins MM, Bates AS \& Stewart PM. ACTH deficiency, higher doses of hydrocortisone replacement, and radiotherapy are independent predictors of mortality in patients with acromegaly. Journal of Clinical Endocrinology and Metabolism 200994 4216-4223. (doi:10.1210/jc.2009-1097)
15 Benson S, Neumann P, Unger N, Schedlowski M, Mann K, Elsenbruch S \& Petersenn S. Effects of standard glucocorticoid replacement therapies on subjective well-being: a randomized, double-blind, crossover study in patients with secondary adrenal insufficiency. European Journal of Endocrinology 2012167 679-685. (doi:10.1530/EJE-12-0351)

16 Johannsson G, Nilsson AG, Bergthorsdottir R, Burman P, Dahlqvist P, Ekman B, Engstrom BE, Olsson T, Ragnarsson O, Ryberg M et al. Improved cortisol exposure-time profile and outcome in patients with adrenal insufficiency: a prospective randomized trial of a novel hydrocortisone dual-release formulation. Journal of Clinical Endocrinology and Metabolism 201297 473-481. (doi:10.1210/jc.2011-1926)

17 Ho KK \& 2007 GH Deficiency Consensus Workshop Participants. Consensus guidelines for the diagnosis and treatment of adults with GH deficiency II: a statement of the GH Research Society in association with the European Society for Pediatric Endocrinology, Lawson Wilkins Society, European Society of Endocrinology, Japan Endocrine Society, and Endocrine Society of Australia. European Journal of Endocrinology 2007157 695-700. (doi:10.1530/EJE-07-0631)

18 McKenna SP, Doward LC, Alonso J, Kohlmann T, Niero M, Prieto L \& Wiren L. The QoL-AGHDA: an instrument for the assessment of quality of life in adults with growth hormone deficiency. Quality of Life Research 19998 373-383. (doi:10.1023/A:1008987922774)

19 Koltowska-Haggstrom M, Hennessy S, Mattsson AF, Monson JP \& Kind P. Quality of life assessment of growth hormone deficiency in adults (QoL-AGHDA): comparison of normative reference data for the general population of England and Wales with results for adult hypopituitary patients with growth hormone deficiency. Hormone Research 200564 46-54. (doi:10.1159/000087444)

20 Hernberg-Stahl E, Luger A, Abs R, Bengtsson BA, Feldt-Rasmussen U, Wilton P, Westberg B \& Monson JP. Healthcare consumption decreases in parallel with improvements in quality of life during $\mathrm{GH}$ replacement in hypopituitary adults with GH deficiency. Journal of Clinical Endocrinology and Metabolism 200186 5277-5281. (doi:10.1210/jcem. 86.11.7997)

21 Danilowicz K, Bruno OD, Manavela M, Gomez RM \& Barkan A. Correction of cortisol overreplacement ameliorates morbidities in patients with hypopituitarism: a pilot study. Pituitary 200811 279-285. (doi:10.1007/s11102-008-0126-2)

22 Groves RW, Toms GC, Houghton BJ \& Monson JP. Corticosteroid replacement therapy: twice or thrice daily? Journal of the Royal Society of Medicine 198881 514-516.

23 Grossman AB. Clinical Review: The diagnosis and management of central hypoadrenalism. Journal of Clinical Endocrinology and Metabolism 201095 4855-4863. (doi:10.1210/jc.2010-0982)

24 Esteban NV, Loughlin T, Yergey AL, Zawadzki JK, Booth JD, Winterer JC \& Loriaux DL. Daily cortisol production rate in man determined by stable isotope dilution/mass spectrometry. Journal of Clinical Endocrinology and Metabolism 199172 39-45. (doi:10.1210/jcem-72-1-39)

25 Husebye ES, Allolio B, Arlt W, Badenhoop K, Bensing S, Betterle C, Falorni A, Gan EH, Hulting AL, Kasperlik-Zaluska A et al. Consensus statement on the diagnosis, treatment and follow-up of patients with primary adrenal insufficiency. Journal of Internal Medicine 2013275 104-115. (doi:10.1111/joim.12162)

26 Arlt $\mathrm{W}$. The approach to the adult with newly diagnosed adrenal insufficiency. Journal of Clinical Endocrinology and Metabolism 200994 1059-1067. (doi:10.1210/jc.2009-0032)

27 Grossman A, Johannsson G, Quinkler M \& Zelissen P. Therapy of endocrine disease: perspectives on the management of adrenal insufficiency: clinical insights from across Europe. European Journal of Endocrinology 2013169 R165-R175. (doi:10.1530/EJE-13-0450)

28 Lindsay JR, Nansel T, Baid S, Gumowski J \& Nieman LK. Long-term impaired quality of life in Cushing's syndrome despite initial improvement after surgical remission. Journal of Clinical Endocrinology and Metabolism 200691 447-453. (doi:10.1210/jc.2005-1058)

29 Iacobone M, Citton M, Viel G, Boetto R, Bonadio I, Mondi I, Tropea S, Nitti D \& Favia G. Adrenalectomy may improve cardiovascular and 
metabolic impairment and ameliorate quality of life in patients with adrenal incidentalomas and subclinical Cushing's syndrome. Surgery 2012152 991-997. (doi:10.1016/j.surg.2012.08.054)

30 Swinburn CR, Wakefield JM, Newman SP \& Jones PW. Evidence of prednisolone induced mood change ('steroid euphoria') in patients with chronic obstructive airways disease. British Journal of Clinical Pharmacology 198826 709-713. (doi:10.1111/j.1365-2125.1988.tb05309.x)

31 Anfinson TJ, Channappa C \& Vo HT. Drug dependence involving prednisone: two cases and a review of the literature. Psychopharmacology Bulletin 200841 154-163.

32 Bleicken B, Hahner S, Loeffler M, Ventz M, Allolio B \& Quinkler M. Impaired subjective health status in chronic adrenal insufficiency: impact of different glucocorticoid replacement regimens. European Journal of Endocrinology 2008159 811-817. (doi:10.1530/EJE-08-0578)

33 Gibney J, Wallace JD, Spinks T, Schnorr L, Ranicar A, Cuneo RC, Lockhart S, Burnand KG, Salomon F, Sonksen PH et al. The effects of 10 years of recombinant human growth hormone (GH) in adult GH-deficient patients. Journal of Clinical Endocrinology and Metabolism 199984 2596-2602. (doi:10.1210/jcem.84.8.5916)

34 Svensson J, Finer N, Bouloux P, Bevan J, Jonsson B, Mattsson AF, Lundberg M, Harris PE, Koltowska-Haggstrom M \& Monson JP. Growth hormone $(\mathrm{GH})$ replacement therapy in GH deficient adults: predictors of one-year metabolic and clinical response. Growth Hormone \& IGF Research 200717 67-76. (doi:10.1016/j.ghir.2006.11.002)
35 Moore JS, Monson JP, Kaltsas G, Putignano P, Wood PJ, Sheppard MC, Besser GM, Taylor NF \& Stewart PM. Modulation of $11 \beta$-hydroxysteroid dehydrogenase isozymes by growth hormone and insulin-like growth factor: in vivo and in vitro studies. Journal of Clinical Endocrinology and Metabolism 199984 4172-4177. (doi:10.1210/jcem.84.11.6108)

36 Tomlinson JW, Walker EA, Bujalska IJ, Draper N, Lavery GG, Cooper MS, Hewison M \& Stewart PM. 11 $\beta$-Hydroxysteroid dehydrogenase type 1: a tissue-specific regulator of glucocorticoid response. Endocrine Reviews 200425 831-866. (doi:10.1210/er.2003-0031)

37 Giavoli C, Libe R, Corbetta S, Ferrante E, Lania A, Arosio M, Spada A \& Beck-Peccoz P. Effect of recombinant human growth hormone (GH) replacement on the hypothalamic-pituitary-adrenal axis in adult GH-deficient patients. Journal of Clinical Endocrinology and Metabolism 200489 5397-5401. (doi:10.1210/jc.2004-1114)

38 Swords FM, Carroll PV, Kisalu J, Wood PJ, Taylor NF \& Monson JP. The effects of growth hormone deficiency and replacement on glucocorticoid exposure in hypopituitary patients on cortisone acetate and hydrocortisone replacement. Clinical Endocrinology 200359 613-620. (doi:10.1046/j.1365-2265.2003.01894.x)

39 Oksnes M, Bensing S, Hulting AL, Kampe O, Hackemann A, Meyer G, Badenhoop K, Betterle C, Parolo A, Giordano R et al. Quality of life in European patients with Addison's disease: validity of the diseasespecific questionnaire AddiQoL. Journal of Clinical Endocrinology and Metabolism 201297 568-576. (doi:10.1210/jc.2011-1901)

Received 17 May 2014

Revised version received 5 August 2014

Accepted 13 August 2014 